\title{
Complicaciones infecciosas en diálisis peritoneal crónica
}

\author{
Rama Nefrología Pediátrica - Sociedad Chilena de Pediatría
}

\author{
PATRICIA BARRERA ${ }^{1}$, PEDRO ZAMBRANO ${ }^{2}$, ANGÉLICA CONTRERAS $^{3}$, PATRICIA DREVES ${ }^{4}$, \\ IGNACIO SALGADO ${ }^{5}$, ANDREA VOGEL ${ }^{6}$, RAÚL ENCALADA ${ }^{7}$, FRANCISCO CANO $^{8}$ \\ 1. Nefrología Infantil, Complejo Asistencial Dr. Sótero del Río, Santiago. \\ 2. Nefrólogo Infantil, Hospital Exequiel González Cortés, Santiago. \\ 3. Nefrólogo Infantil, Hospital Roberto del Río, Santiago \\ 4. Nefrólogo Infantil, Hospital Dr. Hernán Henríquez, Temuco. \\ 5. Nefrólogo Infantil, Hospital Exequiel González Cortés, Santiago. \\ 6. Nefrólogo Infantil, Hospital Clínico de la Pontificia Universidad Católica de Chile, Santiago. \\ 7. Urólogo infantil, Hospital Sótero del Río. \\ 8. Nefrólogo Infantil, Hospital Luis Calvo Mackenna, Santiago. \\ En representación de la Rama de Nefrología de la Sociedad Chilena de Pediatría.
}

\section{Objetivos}

Las presentes recomendaciones están dirigidas a pediatras, enfermeras que se desempeñan a nivel terciario y a los equipos de salud de los programas de diálisis peritoneal infantil (enfermera, nefrólogo y urólogo) a modo de facilitar las decisiones clínicas en los ámbitos de prevención, diagnóstico y tratamiento de complicaciones infecciosas, y generar registros de tasas de infecciones, comparables entre los centros nacionales e internacionales.

\section{Población objetivo}

Los pacientes en los cuales se aplicará la guía, son aquellos con Enfermedad Renal Crónica Terminal en diálisis peritoneal crónica, menores o igual a 18 años.

\section{Recomendaciones según nivel de evidencia}

La publicación reciente de Guías internacionales en Diálisis Peritoneal (adultos y niños) por la Sociedad Internacional de Diálisis Peritoneal y Grupo de Revisión Cochrane han hecho posible un mejor análisis de la información disponible y la generación de estas primeras Guías nacionales. La Guía está organizada en aspectos referidos al diagnostico, tratamiento, prevención y deberán ser entendidas como una recomendación basada en la mejor información disponible y corresponderá a cada centro evaluar caso a caso la adecuación a la situación clínica determinada.

Tabla 1. Grados de Evidencia

\begin{tabular}{ll}
\hline Grado & Tipo de Evidencia \\
\hline I a & Metanálisis de estudios controlados randomizados \\
I b & Al menos 1 estudio controlado randomizado \\
II a & Al menos 1 estudio controlado no randomizado \\
II b & Al menos 1 estudio cuasi-experimental \\
III & Estudios descriptivos no experimentales, como \\
& estudios de correlación y caso-control \\
IV & Opinión de expertos, comités, experiencias clínicas
\end{tabular}

Niveles de Recomendación

\begin{tabular}{ll}
\hline Grado & Fortaleza de las Recomendaciones \\
\hline A & Directamente basada en categoría I de evidencia \\
B & Directamente basada en categoría II de evidencia \\
C & $\begin{array}{l}\text { Directamente basada en categoría III de evidencia, } \\
\text { O extrapoladas de categorías I ó II }\end{array}$ \\
D & $\begin{array}{l}\text { Directamente basada en categoría IV de evidencia, } \\
\text { o extrapoladas de categorías I, II ó III }\end{array}$ \\
\hline
\end{tabular}


Estrategia utilizada para la búsqueda de la evidencia

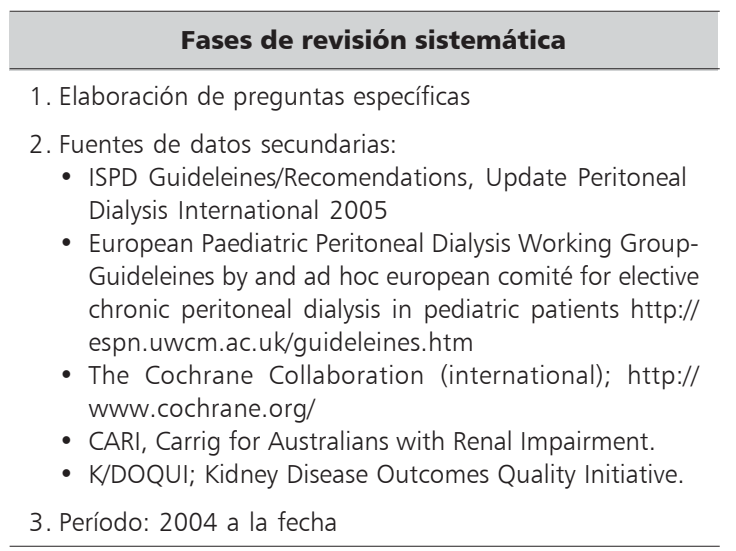

\section{Peritonitis asociada a diálisis peritoneal}

\section{Introducción}

La peritonitis es la principal complicación de los pacientes pediátricos en Diálisis Peritoneal (DP) Ambulatoria tanto en la modalidad manual (CAPD) como en automatizada (APD). La infección puede tener un gran impacto en el pronóstico a largo plazo, disminuyendo el tiempo de vida útil de la membrana peritoneal. Datos del NAPRTCS y USRDS muestran que la peritonitis es la principal causa de hospitalización de niños en DP y la principal causa de transferencia a hemodiálisis.

\section{Diagnóstico de Peritonitis}

Las siguientes son recomendaciones que deben adaptarse a las diferentes situaciones y lugares. Cada centro debería examinar su patrón de infecciones, microorganismos involucrados, sensibilidad a antibióticos y adaptar los protocolos según las condiciones locales.

En todo paciente en diálisis que presenta líquido peritoneal turbio se debe presumir que presenta peritonitis. Esto se confirma mediante el estudio de líquido peritoneal el cual incluye recuento absoluto y diferencial de leucocitos y cultivo (Evidencia)

El diagnóstico de peritonitis se basa en tres elementos:

- Síntomas y signos clínicos.

- Recuento celular del líquido peritoneal.

- Cultivo de líquido peritoneal.
Síntomas y signos en Peritonitis en DP* (Alexander von Graevenitz, Clin Microb Rev, Jan 1992, pp 36-48)

- Dolor abdominal difuso

$70-80 \%$

- Fiebre

$35-60 \%$

- Náuseas

$30-35 \%$

- Vómitos

$25-30 \%$

- Calofríos

- Diarrea

- Problemas de drenaje

$20-25 \%$

$<10 \%$

$15 \%$

- Leucocitosis

$30-45 \%$

- Hemocultivos positivos

Dolor abdominal y fiebre: Inespecíficos, la clínica tiene una sensibilidad y especificidad bajas para predecir peritonitis por lo que se requiere del estudio del líquido peritoneal el que incluye: recuento absoluto y diferencial de leucocitos y cultivo.

Turbidez del líquido peritoneal: Está dada por un recuento celular mayor de 100. Entre 50-100 células puede ser líquido claro.

Diagnóstico diferencial de líquido turbio: Presencia de fibrina, quilo, sangre, peritonitis de otro origen (quirúrgica, química) permanencia de más de 10 horas del dializado en abdomen.

Peritonitis eosinofilica: Se define como la presencia de $>10 \%$ de eosinófilos del total de $\mathrm{PMN}$ en el líquido peritoneal. Ocurre en un paciente asintomático que está iniciando las diálisis. Se produce como una reacción alérgica a los componentes de la solución de diálisis o a sustancias relacionadas con el equipo de diálisis. Es autolimitada.

Dolor abdominal y/o sintomas sistémicos, con Líquido Peritoneal claro: Paciente en APD con recambios de corta permanencia (muy rápidos, diluyen el líquido). Debe hacerse un recambio con 1-2 horas de permanencia y reevaluar la muestra. Es de interés que un $6 \%$ de los adultos con peritonitis con cultivo positivo presentan líquido claro y dolor abdominal, sólo 2/3 de esos pacientes desarrollaron líquido turbio.

\section{Recuento celular en líquido peritoneal}

Diagnóstico de peritonitis debe hacerse ante la presencia de líquido turbio cuyo estudio presente un recuento absoluto de leucocitos mayor 
de 100 leucocitos por $\mathrm{uL}$ y un recuento diferencial con más $50 \%$ de polimorfonucleares.

El porcentaje de polimorfonucleares es un indicador mucho más sensible de peritonitis que el recuento absoluto:

El peritoneo normal tiene muy pocas células PMN por lo que una proporción $>50 \%$ sugiere fuertemente el diagnóstico aún si el recuento absoluto de leucocitos es $<100$.

El recuento absoluto de leucocitos depende del período de tiempo con abdomen húmedo:

- Pacientes en APD nocturna tienen un tiempo húmedo más corto que los que están en CAPD; en este caso es más útil el recuento de PMN que el $\mathrm{N}^{\circ}$ absoluto de leucocitos para hacer el diagnóstico de peritonitis.

- Paciente en APD con abdomen húmedo en el día, tiene un recuento celular similar al que está en CAPD

- Paciente en APD sin recambio diurno, con dolor abdominal, puede no tener suficiente líquido para estudiar. Se debe infundir solución, con una permanencia de 1-2 horas y luego drenar y estudiar

\section{Cultivo de líquido peritoneal}

El estudio microbiológico muestra una menor sensibilidad que la clínica y el recuento celular.

Tinción de Gram: El uso del examen directo o Gram es controvertido pues no tiene buen rendimiento, si es negativo no significa que no haya peritonitis. Una terapia empírica no debiera basarse en este examen. Sí puede ser predictor de infección por hongos lo cual significa iniciar de inmediato terapia antifúngica

Cultivo: Un cultivo (-) no excluye el diagnóstico de peritonitis. Dependiendo de la técnica de siembra se puede tener un $5-20 \%$ de cultivos negativos.

En niños, el 20\% de los episodios de peritonitis pueden tener cultivo (-)

Manejo de la muestra de líquido peritoneal: Cultivo (-) no debe ser superior al 20\% de los casos.

La técnica de cultivo utiliza botella de hemocultivos donde luego de haber centrifugado 50 $\mathrm{ml}$ del líquido peritoneal se siembra el sedimento lo cual tiene un bajo número de cultivos (-) (Evidencia).

\section{Recolección y transporte}

1. La muestra debe ser obtenida de la primera bolsa con líquido turbio observada, donde hay mayor probabilidad de cultivo positivo. Drenar el abdomen y enviar la bolsa completa del efluente a laboratorio.

2. La muestra se mantiene a temperatura ambiente si el procesamiento es inmediato. $\mathrm{Si}$ se procesa después de 1 hora de recolecta$\mathrm{da}$, la muestra debe ser refrigerada pero no congelada.

\section{Procesamiento}

1. Se coloca liquido peritoneal en dos tubos de 50 cc cada uno, centrifugar por 15 minutos a $3000 \mathrm{rpm}$,

2. Descartar asépticamente el sobrenadante

3. resuspender el sedimento en vortex

4. realizar estudio microscópico y gram del sedimento

\section{Siembra}

\section{Cultivo bacteriano}

1. Colocar una gota del sedimento en una placa y $5 \mathrm{ml}$ del mismo en una botella de hemocultivo BacT/alert o BACTEC blood System.

2. Incubar las placas en dióxido de carbono a $35^{\circ}$ por $48 \mathrm{hr}$ y las botellas de hemocultivos por 5-7 días

Placa debe ser incubado en ambiente aeróbico, microaerófilo y anaerobio.

Con estas técnicas tiene sólo un $5 \%$ de cultivos falsos (-)

\section{Cultivo de hongos}

1. Incubar sedimento del líquido peritoneal en Agar Sabourod o agar sangre por 4 semanas a $30^{\circ}$.

\section{Estudio microscópico celular}

Recuento absoluto de leucocitos: Se realiza por conteo en cámara. Si el recuento es mayor a 1000, debe realizarse una dilución 1:101:100 en solución salina y centrifugar a 8000 rpm por 7 minutos y luego contar.

Recuento diferencial: conteo en cámara o hemocitómetro. 


\section{Tratamiento de peritonitis asociada a Diálisis Peritoneal}

Las Guías son sólo recomendaciones, cada centro debe debería examinar su propio patrón de infección, organismos causales y sensibilidad, adaptando los protocolos a las condiciones locales.

\section{Terapia empírica}

La terapia empírica inicial debe cubrir tanto gérmenes gram negativos y positivos. Se recomienda una selección de la terapia empírica, centro-específica, dependiendo de la historia de sensibilidad de los organismos causantes de peritonitis (OPINION).

Gérmenes gram positivos pueden ser cubiertos por vancomicina o cefalosporinas. Gram negativos por cefalosporina de tercera generación o aminoglicósidos. (EVIDENCIA).

La selección de terapia empírica debe ser realizada de acuerdo a la realidad local. Se ha usado cefalosporina para cubrir gram $(+)$, asociada a una segunda droga de amplio espectro que cubra gram (-), incluyendo Pseudomona. Este protocolo ha tenido equivalencia a esquema de vancomicina + una segunda droga contra gram -. Cuando existe meticilino resistencia debe usarse vancomicina. Para cubrir gram negativos pueden utilizarse aminoglicósidos, ceftazidima, cefipime o carbapenem. El uso de quinolonas para cubrir gram (-) en forma empírica solo debe utilizarse si la sensibilidad local apoya su uso. En pacientes alérgicos a penicilina sin uso de aminoglicósidos para cubrir gram (-), se recomienda aztreonam. Se puede desarrollar resistencia con el uso de cefalosporina de espectro extendido y quinolonas.

\section{Aminoglicósidos}

Si bien las terapias prolongadas con aminoglicósidos representan riesgo de nefro y ototoxicidad, su uso por cortos períodos parece seguro, y proporciona adecuada cobertura sobre gram (-). Una dosis intermitente de $40 \mathrm{mg} / \mathrm{lt}$ resulta tan efectiva como una dosis continua de $10 \mathrm{mg} / 1$ en 4 intercambios en pacientes en CAPD. No hay evidencia que cursos cortos de aminoglicósidos dañen la función renal. Tratamientos repetidos o prolongados con amiglicósidos no se justifican si hay otras alternativas posibles. (OPINION). Si inicialmente se usa un aminoglicósido para cubrir gram (-), se recomienda su uso intermitente y evitar su uso prolongado.

\section{Cefalosporina tercera generación}

Ceftazidima y cefipime, son buenas alternativas para cubrir gram negativos. Cefipime, no es destruido por muchas de las betalactamasas que producen los bacilos gram negativos, de manera que in vitro tiene mejor sensibilidad que ceftazidima. El 14\% de los gram negativos son resistente a ceftazidima.

\section{Monoterapia como tratamiento empírico}

IMIPENEM/CILASTATINA $500 \mathrm{mg}$ IP, permanencia de 6 horas, seguido por $100 \mathrm{mg} / 2 / 1 \mathrm{t}$ de solución fue tan efectiva en como cefazolina + ceftazidima en CAPD.

CEFIPIME: carga de $2 \mathrm{~g}$ en permanencia mayor de 6 horas, seguido por $1 \mathrm{~g}$ /día por 9 días, fue tan efectiva como vancomicina + netilmicina.

QUINOLONAS: Levofloxacino oral 300 $\mathrm{mg}$ /día o pefloxacino $400 \mathrm{mg} /$ día, parecen ser alternativas a aminoglicósidos para cubrir gram, alcanzando adecuados niveles en peritoneo, aún en DP con cicladora.

En un estudio las quinolonas fueron similares a tto cefazolina + tobramicina, pero tienen lenta respuesta a $S$. Aureus, por lo que no se recomienda como monoterapia.

CEFALOSPORINA DE PRIMERA GENERACIÓN ORAL: Es posible su uso en casos de peritonitis leves generalmente por $S$. Epidermidis, sensible a estas cefalosporina, en pacientes en que la vía IP o IV, no es factible y tiene poca sintomatología. No se recomienda en casos más graves.

\section{Entrega y estabilidad de drogas}

Vancomicina, aminoglicósidos y cefalosporinas pueden ser mezcladas en la misma bolsa de solución de diálisis, sin pérdida de la bioactividad, sin embargo, deben usarse jeringas distintas, ya que son incompatibles al mezclarla en la jeringa o al adicionarla en una bolsa vacía para reinfundir al paciente. Por lo tanto, esto último no se recomienda. Los Aminoglicósidos tienen incompatibilidad química con penicilinas, 
por lo tanto, no pueden ser usadas simultáneamente. El tiempo de permanencia debe ser de 6 horas como mínimo.

\section{Estabilidad de drogas}

Vancomicina $25 \mathrm{mg} / 128$ días a temperatura ambiente. A mayor $\mathrm{T}^{\mathrm{o}}$ se reduce su estabilidad.

Gentamicina $8 \mathrm{mg} / \mathrm{l} \quad 14$ días, disminuye al mezclar con heparina.

Cefazolina $500 \mathrm{mg} / 1 \quad 8$ días a $\mathrm{T}^{\circ}$ ambiente y 14 días refrigerada.

Ceftazidima $125 \mathrm{mg} / \mathrm{l} \quad 4$ días a $\mathrm{T}^{\mathrm{o}}$ ambiente y 7 días refrigerada

Cefepime

14 días si está refrigerada.

\section{Antibiótico intermitente vs continuo \\ Consideraciones especiales para pacientes en APD:}

Hay poco conocimiento acerca de las dosis intermitentes requeridas en pacientes en APD.

Hay acuerdo en que el uso de antibióticos IP para peritonitis es preferible a la dosis IV en CAPD. Ventajas: La dosis IP, alcanza muy altos niveles de antibióticos a nivel local. Ej. 20 mg gentamicina IP alcanza niveles sobre la CIM de gérmenes sensibles, que no se alcanzarían con dosis equivalentes por vía IV. además las dosis IP, pueden ser administradas en la casa, después de un apropiado entrenamiento. Se evitan las venopunciones. Se recomienda el monitoreo de niveles de vancomicina y aminoglicósidos. El tratamiento puede ser administrado en cada intercambio (dosis continua) o una vez al día (dosis intermitente).

\section{Tratamiento intermitente}

La solución de diálisis debe permanecer en la cavidad peritoneal al menos 6 horas, para permitir la adecuada absorción sistémica. La mayoría de los antibióticos aumentan su absorción durante los episodios de peritonitis (ej. Vancomicina se absorbe $50 \%$ sin peritonitis y aumenta al $90 \%$ con peritonitis).

Hay datos insuficientes si la dosis continua es más eficaz que la intermitente en cefalosporinas de primera generación: Los rápidos intercambios en $\mathrm{DPA}$, pueden conducir a un tiempo inadecuado para alcanzar niveles
IP. Hay pocos datos sobre la eficacia de las Cefalosporinas de primera generación administradas en forma intermitente, particularmente en pacientes con cicladora. Pacientes que reciben una dosis de cefalosporina en la permanencia diurna, tienen niveles IP en la noche bajo la CIM para la mayoría de los organismos. Preocupa que los gérmenes productores de biofilm pueden sobrevivir, provocando recaídas. Una dosis de Cefazolina $500 \mathrm{mg} / \mathrm{lt}$, IP una vez al día, alcanza niveles aceptables en el líquido de diálisis en pacientes en CAPD. Mientras no existan estudios randomizados, se recomienda el uso de cefalosporina de primera generación en forma continua (OPINIÓN).

Hay extensa evidencia de efectividad del uso de aminoglicósidos y vancomicina en dosis intermitente en paciente en CAPD, pero no en APD. Aún cuando hay pocos estudios se recomienda el uso de vancomicina en forma intermitente en APD, con intervalos de 4 a 5 días, manteniendo niveles de $15 \mathrm{ug} / \mathrm{ml}$, monitorizando niveles. Los niveles IP de vancomicina después de la dosis inicial, siempre serán menores que el nivel sérico, por lo tanto necesita mantener niveles sanguíneos más altos que lo habitual. La dosis siguiente debe ser administrada cuando los niveles séricos alcancen los 15 ug/ml. No está aclarada la utilidad de cambiar desde APD a CAPD. Schaeffer, en pacientes en CAPD y APD, encuentra que la dosis intermitente es tan eficaz como la contínua usando glicopéptidos (vancomicina o teicoplanina). También sería eficaz en gram negativos la ceftazidima intermitente. En este estudio, hubo un alto cambio desde intermitente a continuo en peritonitis por gram negativos, aunque los marcadores de severidad de la enfermedad mejoran, siendo la causa principal del cambio el criterio clínico de temor a desenlaces fatales del tratamiento.

\section{Manejo posterior de peritonitis}

Conocido el germen y su sensibilidad el tratamiento antibiótico debería ser ajustado.

La dosis de antibióticos para pacientes anúricos, está preestablecidas en tablas. En pacientes con función renal residual la dosis debe ser incrementada en un $25 \%$ para los antibióticos con excreción renal (EVIDENCIA 
Y OPINIÓN). No se conoce el ajuste de dosis para pacientes transportadores altos, los que pueden tener una más rápida remoción de algunos antibióticos. Hay poca información de dosis recomendada para pacientes en APD. Extrapolar de los pacientes en CAPD, puede llevar a baja dosificación en APD por dos razones:

1. Cualquier intercambio que no sea tan prolongado como el diurno, pudiera impedir que la absorción hacia la circulación sistémica. Este problema se evita, asegurando una permanencia mínima de 6 horas durante el día.

2. Algunos datos sugieren que APD, puede tener un mayor clearance de antibióticos que CAPD, resultando en concentraciones reducidas en dializado, suero y posibilidad de intervalos prolongados durante el día con concentraciones en el dializado menores que las CIM para organismos susceptibles.

\section{Medicamentos comúnmente usados y estudiados en APD y dosis recomendada}

\begin{tabular}{ll}
\hline Droga & Dosis intraperitoneal \\
\hline Vancomicina & $\begin{array}{l}\text { Carga: } 30 \mathrm{mg} / \mathrm{k} \text { IP permanencia larga, } \\
\text { repetir dosis } 15 \mathrm{mg} / \mathrm{k} \text { IP permanencia } \\
\text { larga cada } 3-5 \mathrm{días} \text {. Monitoreo nive- } \\
\text { les. (Opinión) }\end{array}$ \\
Cefazolina & $20 \mathrm{mg} / \mathrm{kg}$ día, permanencia larga \\
Tobramicina & Carga: $1,5 \mathrm{mg} / \mathrm{k} \mathrm{IP}$ permanencia larga \\
& $\begin{array}{l}\text { Mantención: 0,5 mg/k IP día en per- } \\
\text { manencia larga }\end{array}$ \\
Fluconazole & $\begin{array}{l}200 \mathrm{mg} \text { IP en un intercambio al día } \\
\text { cada } 24 \text { a } 48 \text { horas }\end{array}$ \\
Cefepime & $1 \mathrm{~g} \mathrm{IP} \mathrm{en} \mathrm{un} \mathrm{intercambio} \mathrm{día} \mathrm{(evidencia}$ \\
& de datos no publicados) \\
\hline
\end{tabular}

\section{Staphylococcus coagulasa negativo}

Estas peritonitis incluyen a $S$. Epidermidis y son debidas a contaminación por contacto, es generalmente leve, responde rápidamente a tratamiento, a veces provoca recaídas debido a la formación de biofilm. En estos casos se indica reemplazo de catéter (EVIDENCIA).

En algunos programas tienen alta tasa de meticilino resistencia $(>50 \%)$, en estos casos el tratamiento empírico debe iniciarse con vancomicina. Los programas de $\mathrm{PD}$, deberían solicitar a los laboratorios que la RESISTENCIA esté basada sobre niveles de CIM.
METICILINO RESISTENCIA indica que el germen se considera resistente a todos los antibióticos beta lactámicos, incluyendo: penicilinas, cefalosporinas, y carbapenemes. Deben evitarse niveles inadecuados que puedan conducir a recaídas. No existen datos suficientes para recomendar dosis intermitentes en cefalosporina de primera generación, por lo que sugiere la dosis continua. Idealmente la terapia debe guiarse con mediciones frecuentes del recuento celular y cultivos del efluente. Duración del tratamiento 2 semanas. Revisar la técnica para evitar recurrencias.

\section{Streptococos y enterococos}

Tienden a ser severas y son mejor tratadas con ampicilina IP (opinión).

Enterococo fecalis resistente a vancomicina (VREF), ha sido excepcionalmente reportado en DP. En general causan dolor severo. Si es sensible ampicilina $125 \mathrm{mg} / \mathrm{l}$ en cada intercambio continúa siendo la droga de elección. Puede adicionarse un aminoglicósido sinérgico, para Enterococo, si no hay evidencia de altos niveles de resistencia antibiótica. La peritonitis por Enterococo, puede ser causado por patología intra-abdominal y contaminación por contacto. Ambos gérmenes, pueden asociarse con infecciones del OS o Túnel. VREF, a menudo se asocia a hospitalización reciente, tratamiento antibiótico previo. Linezolid o quinupristin/ dalfopritin. Deberían ser usados para tratar a VREF (OPINIÓN).

\section{Staphylococcus aureus}

Causa peritonitis severa, puede ser debida a contaminación por contacto, sin embargo a menudo es por infección del catéter. Estas última es poco probable que responda a tratamiento sin remoción del catéter. Se debe evaluar cuidadosamente el OS y el túnel. Si el episodio ocurre concomitante con infección de OS, a menudo la infección será refractaria y el catéter debe ser removido. Después de un período de 2 semanas puede ser reinstalado. (OPINION). Si la cepa es meticilino resistente, usar Vancomicina. Duración del tratamiento: 3 semanas. S. aureus resistente a vancomicina se han reportado en DP. Tratamientos: linezolid, daptomicina, o quinupristin/dalfopristin. 


\section{Pseudomona Aeruginosa}

A menudo asociada a infección del catéter, en estos casos se requiere la remoción del catéter.

El tratamiento siempre debe ser asociado (EVIDENCIA). Duración del tratamiento 2 semanas.

Puede usarse una quinolona. Drogas alternativas: Ceftazidima, cefepime, tobramicina o piperacilina.

\section{Peritonitis con cultivo negativo}

Los Programas con tasas de cultivos negativos $>20 \%$, deberían revisar y mejorar los métodos de cultivos (OPINIÓN). Si no hay crecimiento bacteriano al día 3 , repetir recuento celular y diferencial, si la infección no está resuelta utilizar cultivos especiales: hongos, mycobacterias, Legionella. Si hay mejoría clínica, puede continuar tratamiento, aunque se advierte contra la terapia continua con aminoglicósidos, para peritonitis con cultivo negativo. Duración del tratamiento 2 semanas. Si al 5 día no hay mejora: REMOCIÓN DEL CATÉTER.

\section{Sugerencias para investigación futura}

Ya que se plantea que el tratamiento empírico es centro específico, sería útil que cada hospital informe de sus gérmenes prevalentes. Hay fuerte evidencia que los aminoglicósidos son altamente efectivos para $S$. aureus y Gram negativos.
Tanto en el estudio europeo como en la experiencia del Hospital Roberto del Río, cerca del $40 \%$ de las peritonitis son causadas por S. Aureus o Gram negativos. Las guías pediátricas internacionales de peritonitis propondrán a futuro el uso de Aminoglicósidos por sobre las cefalosporina de tercera generación.

Los esquemas propuestos como tratamientos empíricos serían (ver tablas 1, 2 y 3):

- Cefalosporina primera generación + Aminoglicósidos

- Cefalosporina de primera generación + Ceftazidima

- Vancomicina + Aminoglicósidos

- Vancomicina + Ceftazidima

\section{Retiro del catéter de diálisis peritoneal}

Se recomienda retirar el catéter de diálisis peritoneal en (Evidencia Nivel III y IV) peritonitis refractaria al tratamiento, recaída de peritonitis, infección refractaria del sitio de salida y de la infección del túnel, peritonitis por hongos.

No hay un consenso sobre la reinserción del catéter de diálisis peritoneal después de su retiro, se sugiere esperar 2 a 3 semanas entre el retiro y la reinserción del catéter (Opinión); cada caso requiere evaluación individual; transitoriamente el paciente deberá cambiar de modalidad dialítica (hemodiálisis) mientras se coloca el nuevo catéter. En casos de recaída de peritonitis, con líquido claro, la instalación simultánea podría realizarse (Opinión).

Tabla 1. Tratamiento para peritonitis por gérmenes gram positivos

Hora 0: Iniciar tratamiento con cefazolina o cefalotina y ceftazidima o glicopéptidos (vancomicina o teicoplanina) y ceftazidima 24-48 horas (según sensibilidad)

\begin{tabular}{|c|c|c|}
\hline Enterococos streptococos & Staphylococcus aureus & Otros gram positivos \\
\hline \multirow{3}{*}{$\begin{array}{l}\text { Descontinuar ceftazidima o glicopéptidos } \\
\text { e iniciar: Ampicilina: } 125 \mathrm{mg} / \mathrm{l} \\
\text { En caso de resistencia a ampicilina usar } \\
\text { vancomicina o clindamicina } \\
\text { Pueden agregarse aminoglucósidos } \\
\text { según sensibilidad del germen }\end{array}$} & $\begin{array}{l}\text { Meticilino sensible: continar cefalosporina } \\
\text { Suspender ceftazidima o glicopéptidos }\end{array}$ & $\begin{array}{l}\text { Meticilino sensibles: Descontinuar cefta- } \\
\text { zidima y glicopéptidos }\end{array}$ \\
\hline & $\begin{array}{l}\text { Considerar uso de rifampicina } 20 \text { mg/ } \\
\text { /kg/día vo en } 3 \text { dosis (máximo } 600 \text { mg) }\end{array}$ & Continuar cefalosporinas \\
\hline & $\begin{array}{l}\text { Meticilino resistente: Descontinuar } \\
\text { ceftazidima, continuar con glicopéptidos }\end{array}$ & \\
\hline \multicolumn{3}{|c|}{$\begin{array}{l}\text { HORA 96: } \\
\text { - Si no hay mejoría, tomar cultivos y reevaluar } \\
\text { - Considerar ecotomografía para evaluar infección oculta del túnel } \\
\text { - Para peritonitis con infección del sitio de salida considerar remover el catéter }\end{array}$} \\
\hline 14 días & 21 días & 14 días \\
\hline
\end{tabular}


Tabla 2. Tratamiento para peritonitis por germenes gram negativos

\begin{tabular}{|c|c|c|}
\hline $\begin{array}{l}\text { Germen gram negativo único } \\
\text { (no Stenotrophomonas) }\end{array}$ & Pseudomonas o Stenotrofomonas & Gérmenes múltiples o anaerobios \\
\hline $\begin{array}{l}\text { Puede utilizarse ceftazidima } \\
\text { Ajustar según antibiograma }\end{array}$ & $\begin{array}{l}\text { Suspenda cefalosporina o glicopéptidos; } \\
\text { continuar con ceftazidima }\end{array}$ & $\begin{array}{l}\text { Considerar intervención quirúrgica, } \\
\text { añadir metronidazol } 15 \mathrm{mg} / \mathrm{kg} / \mathrm{día} \\
\text { cada } 8 \text { horas (máximo 1,5 g/día) } \\
\text { VO, EV, o rectal }\end{array}$ \\
\hline
\end{tabular}

HORA 96:
- Si hay mejoría mantener tratamiento
- Si no hay mejoría, repetir estudio de líquido peritoneal
- Si el cultivo persiste positivo remover catéter
- Si no hay mejoría clínica e infección del sitio de salida, remover catéter

14 días 21 días 21 días

Tabla 3. Antibióticos orales para infección del orificio de salida y del túnel

\begin{tabular}{ll}
\hline Antibioticos & Dosis \\
\hline Amoxicilina & $80 \mathrm{mg} / \mathrm{kg} / \mathrm{día}$ \\
Cefazolina & $15 \mathrm{mg} / \mathrm{kg} /$ dosis \\
Ciprofloxacino & $15 \mathrm{mg} / \mathrm{kg} / \mathrm{día}$ \\
Flucloxacilina & $15 \mathrm{mg} / \mathrm{kg} /$ dosis \\
Trimetroprim/Sulfametoxazol & $1,5-3 \mathrm{mg} / \mathrm{kg}$ dosis \\
\hline
\end{tabular}

En relación a la vía de administración recomendamos utilizar en forma primaria tratamiento por vía intraperitoneal, el uso de antibióticos por vía EV se recomienda sólo en casos específicos como retiro del catéter, o suspensión transitoria de la terapia dialítica.

Peritonitis por Hongos: factores de riesgo son, quiebre en la técnica, uso previo de antibióticos (1 mes), la peritonitis bacteriana previa (1 m), inmunodeficiencias, HIV, corticoides, cirugía abdominal, cuerpos extraños (prótesis, sondas), micosis cutánea u oral, contaminación del ambiente: tierra, inmersión.

\section{Recomendaciones basadas en evidencia}

- La evidencia existente es insuficiente para establecer con claridad la mejor elección de agente antifúngico, la duración del tratamiento o para recomendar la remoción del catéter.
- El tratamiento con un agente antifúngico apropiado debería iniciarse tan pronto como la peritonitis por hongos se diagnostica y la remoción del catéter debería realizarse si la condición del paciente no es buena o no mejora después de 2 a 3 días de tratamiento.

- La terapia inicial podría incluir tanto el retiro precoz del catéter como la terapia antifúngica (Evidencia nivel III y IV).

- Con el fin de disminuir la incidencia de la peritonitis por hongos se debería considerar la administración simultánea de nistatina oral (500 $000 \mathrm{U} \mathrm{4v/día)} \mathrm{cuando} \mathrm{se} \mathrm{administren}$ antibióticos a los pacientes en DP, especialmente frente a tratamientos antibióticos prolongados o frecuentes (Evidencia Nivel II).

La Sugerencia de manejo incluye: (OPINIÓN)

- Confirmar la etiología por tinción de Gram y/o cultivo.

- Anfotericina ev: dosis de carga: $1 \mathrm{mg} / \mathrm{kg}$, luego seguir con $1 \mathrm{mg} / \mathrm{kg} / \mathrm{dia}$. No usar por vía intraperitoneal, produce dolor y reacción química inflamatoria.

- Fluconazol intraperitoneal, oral o ev 3-6 mg/ $\mathrm{kg} / \mathrm{dia}$, con una dosis máxima de $200 \mathrm{mg}$, usar en 1 baño de 3-6 hrs.

- Fluocytosina, oral ó ev, dosis de carga de 50 $\mathrm{mg} / \mathrm{kg}$ ( $\mathrm{mx} 2$ grs), luego seguir con una dosis diaria de $30 \mathrm{mg} / \mathrm{kg}$, mx 1 gr. Evaluar toxicidad medular. 
Tabla 4. Dosis recomendada de Antibióticos Intraperitoneal (excepto se indique otra vía de administración)

\begin{tabular}{|c|c|c|c|}
\hline Antibióticos & $\begin{array}{l}\text { Terapia contínua } \\
\text { Dosis de carga }\end{array}$ & $\begin{array}{l}\text { Terapia contínua } \\
\text { Dosis mantención }\end{array}$ & Terapia intermitente \\
\hline \multicolumn{4}{|l|}{ Glicopéptidos } \\
\hline Vancomicina & $1000 \mathrm{mg} / \mathrm{L}$ & 30 mg/L & 30 mg/kg c/ 5-7 días \\
\hline Teicoplanina & $400 \mathrm{mg} / \mathrm{lL}$ & $20 \mathrm{mg} / \mathrm{L}$ & $15 \mathrm{mg} / \mathrm{kg} \mathrm{c} / 5-7$ dias \\
\hline \multicolumn{4}{|l|}{ Cefalosporinas } \\
\hline Cefazolina cefalotina & 500 mg/L & 125 mg/L & $15 \mathrm{mg} / \mathrm{kg} \mathrm{c} / 24$ horas \\
\hline Cefuroxima & 200 mg/L & 125 mg/L & $15 \mathrm{mg} / \mathrm{kg} \mathrm{c} / 24$ horas \\
\hline Cefotaxima & $500 \mathrm{mg} / \mathrm{L}$ & $250 \mathrm{mg} / \mathrm{L}$ & $30 \mathrm{mg} / \mathrm{kg} \mathrm{c} / 24$ horas \\
\hline Ceftazidima & $250 \mathrm{mg} / \mathrm{L}$ & $125 \mathrm{mg} / \mathrm{L}$ & $15 \mathrm{mg} / \mathrm{kg} \mathrm{c} / 24$ horas \\
\hline \multicolumn{4}{|l|}{ Antifúngicos } \\
\hline Anfotericina B & $1 \mathrm{mg} / \mathrm{kg} \mathrm{EV}$ & $1 \mathrm{mg} / \mathrm{kg} / \mathrm{día}$ EV & \\
\hline Fluconazol & & $\begin{array}{l}3-6 \mathrm{mg} / \mathrm{kg}, \mathrm{IP}, \mathrm{EV}, \mathrm{O} V \mathrm{~V} \\
\mathrm{c} / 24-48 \text { horas }\end{array}$ & \\
\hline Flucitosina & 50 mg/kg EVoVO (máx. 2 gr) & $25-37,5 \mathrm{mg} / \mathrm{kg}$ VO & \\
\hline & & c/24 horas (máx.1 gr) & \\
\hline \multicolumn{4}{|l|}{ Aminoglicósidos } \\
\hline Amikacina & $25 \mathrm{mg} / \mathrm{L}$ & $12 \mathrm{mg} / \mathrm{L}$ & \\
\hline Gentamicina & & $8 \mathrm{mg} / \mathrm{L}$ & $4 \mathrm{mg} / \mathrm{L}$ \\
\hline Netilmicina & $8 \mathrm{mg} / \mathrm{L}$ & $4 \mathrm{mg} / \mathrm{L}$ & \\
\hline Tobramicina & $8 \mathrm{mgL}$ & $4 \mathrm{mg} / \mathrm{L}$ & \\
\hline \multicolumn{4}{|l|}{ Penicilinas } \\
\hline Azlocilina & 500 mg/L & 250 mg/L & \\
\hline Piperacilina & & $250 \mathrm{mg} / \mathrm{L}$ & $150 \mathrm{mg} / \mathrm{kgEV} \mathrm{c} / 12$ horas \\
\hline Ampicilina & & 125 mg/L & \\
\hline Oxacilina & & 125 mg/L & \\
\hline Nafcilina & & $125 \mathrm{mg} / \mathrm{L}$ & \\
\hline Amoxicilina & $250-500 \mathrm{mg} / \mathrm{L}$ & $50 \mathrm{mg} / \mathrm{L}$ & \\
\hline \multicolumn{4}{|l|}{ Quinilonas } \\
\hline Ciprofloxacino & $50 \mathrm{mg} / \mathrm{L}$ & $25 \mathrm{mg} / \mathrm{L}$ & \\
\hline \multicolumn{4}{|l|}{ Combinaciones } \\
\hline Ampicilina /Sulbactan & 1000 mg/L & 100 mg/L & \\
\hline Imipenem/Cilastatina & $500 \mathrm{mg} / \mathrm{L}$ & $200 \mathrm{mg} / \mathrm{L}$ & \\
\hline Trimetropin/Sulfa & $320 / 1.600 \mathrm{mg} / \mathrm{L}$ & $80 / 400 \mathrm{mg} / \mathrm{L}$ & \\
\hline \multicolumn{4}{|l|}{ Otros } \\
\hline Clindamicina & 300 mg/L & 150 mg/L & \\
\hline Metronidazol & & & 35-50 mg/kg/día VO en 3 dosis \\
\hline Rifampicina & & & $20 \mathrm{mg} / \mathrm{kg} / \mathrm{d}$ ía VO (máx. 600 mg/día) \\
\hline Aztreonan & 1.000 mg/L & 250 mg/L & \\
\hline
\end{tabular}

- Caspofungin, puede ser usada en pacientes adultos, $70 \mathrm{mg}$ el dia 1 , via ev, luego $50 \mathrm{mg}$ al dia, pasar ev lento, en 1 hora.

- Voriconazole, útil como monoterapia en Candida sp y Aspergillus. En mayores de $2 \mathrm{a}, 6 \mathrm{mg} / \mathrm{kg}$ máximo $200 \mathrm{mg}$ hasta $\operatorname{los} 40 \mathrm{~kg}$, $400 \mathrm{mg}$ en los mayores de $40 \mathrm{~kg}$. Repetir dosis a las $12 \mathrm{hrs}$, luego seguir cada $12 \mathrm{hrs}$ con $4 \mathrm{mg} / \mathrm{kg}$ en el mayor de 2 a y menos de $40 \mathrm{~kg}, 100 \mathrm{mg}$ maximo. En el mayor de 40 $\mathrm{kg}$, seguir con $200 \mathrm{mg}$ cada $12 \mathrm{hrs}$.

- La duración del tratamiento debería ser 2 semanas o más y hasta la completa resolución de los síntomas. En aquellos casos en que no se haya removido el cáteter debe ser al menos 4 a 6 semanas.

\section{Uroquinasa en diálisis peritoneal crónica (Recomendaciones Nivel III-IV)}

\section{Antecedentes}

El uso de la uroquinasa parece una terapia lógica, dado su potencial para disolver coágulos de fibrina que obstruyen el catéter de diálisis, y 
para disolver el biofilm que recubre su lumen, en el cual se alojan los microorganismos que causan la peritonitis.

Sin embargo, el uso de antibióticos y reemplazo del catéter ha sido superior al uso de antibióticos más uroquinasa en el manejo de peritonitis (Nivel II). En una revisión de los reportes de uso de uroquinasa los autores recomiendan reservar su uso para aquellos pacientes con peritonitis recurrente o persistente con contraindicación de remoción del catéter.

Actualmente la evidencia disponible no apoya ni rechaza su uso (CARI, 2004)

Indicaciones: 1) Obstrucción de catéter de diálisis peritoneal; 2) Peritonitis resistente a tratamiento (falta de respuesta después de 4 días de tratamiento con apropiada antibioterapia, o 3 episodios de peritonitis en 6 meses).

\section{Método de aplicación}

1. Cambiar el adaptador del catéter de Tenckhoff.

2. Instilar Uroquinasa, $5000 \mathrm{U} / \mathrm{ml}$ en cantidad suficiente para llenar el lumen del catéter, dejar in situ por 3 horas, durante 3-5 días.

3. Luego de retirar la Uroquinasa dejar el antibiótico usado para la peritonitis, in situ (50 $\mathrm{mg} / \mathrm{ml}$ ), luego retirar.

4. Mantener tratamiento de peritonitis por los tiempos recomendados.

\section{Prevención de peritonitis asociada a diálisis peritoneal}

Las medidas actualmente recomendadas están basadas en la opinión y experiencia de expertos, (ver ISPD 2004, CARI, 2004).

Medidas de prevención relacionadas con el catéter de DP:

Una reciente Revisión del Grupo Cochrane (2004) y un metanálisis relacionado (Stripolli, JASN 2004) estudió diferentes intervenciones relacionadas con el catéter de DP, tales como el diseño de éste, la técnica de inserción, los sistemas de conexión y la modalidad de DP usada. Si bien el número de pacientes involucrados fue alto (1 089 y 2822 respectivamente) la calidad de los estudios analizados fue subóptima. La Guía Australina CARI aunque de publicación anterior a estos metaanálisis com- parte las conclusiones fundamentales y sus recomendaciones son:

\section{Técnica de inserción}

No existe técnica de inserción que haya probado consistentemente ser superior a otra en la prevención de peritonitis (evidencia nivel II)

Existen dos estudios aleatorios (randomizados) que comparan la incisión medial versus la incisión lateral que no muestran diferencias en la incidencia de peritonitis. Sólo un estudio aleatorio comparara inserción quirúrgica abierta vs laparoscópica que no muestra diferencias en peritonitis y otro estudio que compara cirugía abierta vs inserción por peritoneoscopía muestra reducción en la peritonitis precoz a las dos semanas en el grupo de peritoneoscopía.

Hay 4 estudios aleatorios que comparan dejar el catéter en un bolsillo subcutáneo (y exteriorizarlo a los 15 días) vs la técnica tradicional (exteriorización inmediata). Un estudio muestra menos peritonitis en el grupo del bolsi1lo subcutáneo, 2 no muestran diferencias y el tercero no muestra diferencias en la incidencia de peritonitis pero la probabilidad acumulada a los 18 meses de desarrollar peritonitis es menor en el grupo bolsillo subcutáneo.

\section{Tipo o diseño del catéter de DP}

Para prevenir peritonitis ningún catéter ha probado ser superior al catéter Tenckhoff estándar de dos cuff (Evidencia Nivel II)

Hay 7 estudios randomizados que comparan los diferentes tipos de catéteres manguito (cuff) simple o doble, Tenckhoff recto y enroscado, Toronto-Western, y cuello de cisne recto y enroscado, los cuales mostraron que NO hay diferencias significativas en la incidencia de peritonitis.

Información proveniente de estudios no aleatorios sugiere una menor tasa de peritonitis asociada a infección del OS/túnel al orientar el OS del catéter de DP hacia abajo en lugar de una orientación horizontal o hacia arriba.

\section{Medidas de prevención relacionadas con la administración de antibióticos}

- Antibióticos profilácticos en la inserción del catéter de diálisis peritoneal: 
- Para reducir la incidencia de peritonitis se debería usar profilaxis antibiótica con una cefalosporina de primera generación en el momento de la inserción del catéter de diálisis peritoneal (Evidencia Nivel II).

- Si bien la Vancomicina profiláctica también ha demostrado ser efectiva (Nivel II), su uso rutinario no se recomienda por el potencial desarrollo de microorganismos resistentes.

- La profilaxis intravenosa preoperatoria reduce la peritonitis temprana pero no la infección del sitio de salida/túnel (Rev Cochrane, 2004).

Existen cuatro estudios randomizados que evalúan si la administración de antibióticos profilácticos antes de la inserción del catéter de PD reduce la incidencia de peritonitis, tres de ellos muestran una reducción significativa con periodos cortos de seguimiento de menos de cuatro semanas. Uno de ellos muestra ventajas de la Vancomicina sobre la Cefazolina.

\section{Uso profiláctico de mupirocina}

La terapia profiláctica usando ungüento de mupirocina, especialmente para los portadores nasales de Staphylococcus aureus, intranasal se recomienda para reducir el riesgo de infección del OS/túnel por S. aureus (Evidencia Nivel II). La mupirocina nasal reduce la infección del sitio de salida/túnel pero no la peritonitis (Cochrane, 2004).

\section{Recomendaciones (basadas en evidencia nivel III y IV)}

- El uso diario de mupirocina no parece conducir a niveles significativos de resistencia en el corto plazo (Vas et al, 1999), pero éstos niveles aumentan con períodos de uso mas prolongados (Pérez-Fontan et al 2002) y después de 4 años puede llegar a ser un problema significativo (Annigeri 2001).

- Se recomienda la terapia profiláctica con ungüento de mupirocina en el OS especialmente para la portación de $S$. aureus para reducir el riesgo de infecciones por $S$. aureus en OS/túnel y peritonitis (Bernardini 1996).

\section{Medidas de prevención relacionadas con} los sistemas de conexión y modalidad de diálisis

- Los sistemas de conexión- desconexión (doble-bolsa, conexión en Y) son superiores a los sistemas que implican espigar (puncionar) las bolsas de PD. (Evidencia Nivel I).

- La modalidad de diálisis automatizada (APD) no ha demostrado ser superior a la modalidad manual (CAPD) a pesar del mayor número de conexiones que esta última implica. Los datos de una menor incidencia de peritonitis en APD provienen de estudios no aleatorios.

- La soluciones con icodextran no han demostrado ser superiores a la glucosa para disminuir la peritonitis cuando se usan en baños prolongados en CAPD (Evidencia Nivel II).

\section{Registro de tasas de peritonitis}

Objetivos

- Conocer la tasa de infección de cada unidad de peritoneodiálisis.

- Evaluar la tendencia local con el fin de implementar estrategias como técnicas educativas, tecnologías, infraestructura, protocolos, etc.

Tasa global del programa: Existen varias formas de expresar la tasa:

- peritonitis en x unidad de tiempo (paciente/ año, paciente/mes)

- $\mathrm{n}$ peritonitis /paciente/año (mes)

- peritonitis cada $n$ meses

\section{Cálculo}

1. Determinar el número de paciente/año/experiencia:

Sumar el número total de pacientes/días de experiencia de DP en la unidad y dividir por 365 días del año:

Pacientes (días acumulados en DP)/ 365

2. Dividir el número de pacientes/año/experiencia por el número de episodios observado

Pacientes/año/experiencia $=1$ episodio/ $\mathrm{n}^{\mathrm{o}}$ de peritonitis $\mathrm{n}$ pacientes/año 
3. Dividir 1 por el número de peritonitis/paciente/año

1
Peritonitis/paciente/año $\begin{gathered}\text { episodios de peritonitis/ } \\ \text { paciente/año }\end{gathered}$

Ejemplo:

$\begin{gathered}12.364 \text { paciente/días } \\ 365 \text { días/año }\end{gathered}$
$\begin{gathered}33,87 \text { paciente/año/ } \\ \text { experiencia }\end{gathered}$

33,87 paciente/año/experiencia $=1,25$

27 episodios de peritonitis

La unidad tiene 1 episodio de peritonitis cada 1,25 pacientes/año.

$$
\begin{gathered}
1, \quad=0,8 \text { episodios de perito- } \\
\begin{array}{c}
1,25 \text { episodio de } \\
\text { peritonitis/pac/año }
\end{array}
\end{gathered}
$$

La unidad tiene 0,8 episodios por cada 1 paciente/año. Valor deseado: 0,2-0,7.

En forma similar se puede calcular la tasa individual de cada paciente, considerando solo "sus" días/paciente y expresarlo en términos de episodios de peritonitis por número de pacientes/mes.

1. Determinar el número de pacientes/mes de experiencia:

Es la experiencia en días que tiene cada paciente en el programa. Se obtiene:

- Sumando los días que cada paciente completó al final del período de evaluación.

- Dividir este dato por 30.42, que corresponde al promedio de los días/mes en 1 año.

2. Dividir el número de pacientes/mes de experiencia por el número de episodios de peritonitis en ese lapso de tiempo.

3. Dividir 1 por el número de paciente/mes para tener 1 peritonitis.

$$
\begin{gathered}
1 \\
\text { peritonitis/pac/mes }
\end{gathered}=\begin{gathered}
\text { episodios de peritonitis/ } \\
\text { paciente/mes }
\end{gathered}
$$

Intervalo libre de infección

El valor deseado es de 1 episodio cada 18 meses $(0,67$ por año). Cálculo:

$$
\frac{\text { Meses de diálisis en riesgo }}{\mathrm{N}^{\circ} \text { de peritonitis en ese tiempo }}
$$

Es una forma frecuente de expresar la tasa global del centro.

El tipo de diálisis peritoneal puede tener un importante rol en la frecuencia de infección.

- Pacientes con diálisis automatizada nocturna (cicladora en la noche con día seco) pueden tener un riesgo menor de infección comparado con diálisis peritoneal continua cíclica (CCPD, cicladora en la noche con día húmedo). Esto porque el abdomen vacío en parte del día aumenta las funciones inmunológicas.

- La literatura describe el riesgo relativo de peritonitis en CCPD versus Diálisis Peritoneal Continua Ambulatoria (CAPD).

- Varios estudios muestran que los pacientes en CCPD tienen un menor riesgo de peritonitis comparados con los pacientes que están con CAPD.

- La reutilización de cassette y líneas de cicladora puede generar un alto riesgo de peritonitis por microorganismos que crecen en ambiente húmedo: conducta proscrita.

\section{Resumen de medidas recomendadas para la prevención de peritonitis asociada a diálisis peritoneal en niños}

\section{Medidas relacionadas al catéter peritoneal}

a. Utilizar un catéter Tenckhoff enroscado con doble cuff y tipo cuello de cisne (swanneck). Elegir según edad y peso: menor de 1 mes: $38,8 \mathrm{~cm}$, infantil: $42 \mathrm{~cm}$, adulto: $62,2 \mathrm{~cm}$ [OPINIÓN].

b. Preferir instalación quirúrgica por cirujano experimentado, vía de abordaje y técnica quirúrgica según experiencia del cirujano [OPINIÓN].

c. Si las condiciones lo permiten esperar un tiempo de cicatrización de al menos 2 semanas antes de usar el catéter [OPINIÓN].

d. La orientación del orificio de salida debe ser hacia abajo (propia del catéter tipo swan neck) [EVIDENCIA Y OPINIÓN].

\section{Medidas relacionadas al uso de antibióticos}

a. Profilaxis antibiótica pre-operatoria con cefalosporina $1^{\mathrm{a}}$ generación [EVIDENCIA]. 
Se utilizará vancomicina sólo en caso de colonización conocida a germen meticilino resistente [OPINIÓN].

b. Utilizar mupirocina intranasal o en sitio de salida en portadores nasales de $S$. Aureus (S.Aureus) [EVIDENCIA]. Se recomienda el uso intranasal por 3 días mensualmente y control con cultivos [OPINIÓN].

c. Profilaxis antibiótica frente a procedimientos invasivos, quiebres de técnica o filtración peri-catéter [OPINIÓN].

\section{Medidas relacionadas con los sistemas de conexión y modalidad de DP}

a. Los sistemas de desconexión (twin-bag) deben preferirse sobre los sistemas que impliquen espigar o puncionar las bolsas o matraces de diálisis (sistemas "abiertos") [EVIDENCIA].

b. La modalidad de diálisis automatizada NO ha demostrado categóricamente ser superior a la modalidad manual (CAPD) en la prevención de peritonitis.

\section{Medidas relacionadas con estrategias educativas y registro de episodios}

a. El tiempo empleado en la educación previo al inicio de DP es inversamente proporcional a la tasa de infecciones, por lo que deben dedicarse esfuerzos especiales para contar con profesionales capacitados que realicen esta tarea [OPINIÓN].

b. Después de cada episodio de peritonitis se debe re-educar y entrenar a los cuidadores encargados de la DP [OPINIÓN].

c. Los Programas de DP pediátrica deberán llevar registro y calculo de tasas de todas las infecciones asociadas a DP incluyendo peritonitis, infección de OS/ túnel, asimismo tasas individuales por paciente y por germen [OPINIÓN].

\section{Infecciones del orificio de salida y túnel subcutáneo}

\section{Diagnóstico (Recomendación basada en Evidencia Nivel III y IV)}

La infección se sospecha por la presencia de secreción purulenta en el orificio de salida, ya sea en forma espontánea o al "exprimir" el túnel. El edema, la sensibilidad y/o eritema importante o persistente sin secreción también pueden indicar infección.

\section{Score para diagnóstico de infección del orificio de salida. Infección OS: $\geq 4$}

\begin{tabular}{llll}
\hline Puntaje & $\mathbf{0}$ & $\mathbf{1}$ & $\mathbf{2}$ \\
\hline Edema & No & $\begin{array}{l}<0,5 \mathrm{~cm}, \\
\text { sólo en OS }\end{array}$ & $\begin{array}{l}>0,5 \mathrm{~cm} \text {, incluye } \\
\text { parte del túnel }\end{array}$ \\
Costra & No & $<0,5 \mathrm{~cm}$ & $>0,5 \mathrm{~cm}$ \\
Eritema & No & $<0,5 \mathrm{~cm}$ & $>0,5 \mathrm{~cm}$ \\
$\begin{array}{l}\text { Dolor a la } \\
\text { presión }\end{array}$ & No & Leve & Importante \\
Secreción & No & Serosa & Purulenta \\
\hline
\end{tabular}

La infección del túnel subcutáneo generalmente ocurre en presencia de infección del OS, y se sospecha por eritema, dolor o edema sobre el trayecto de éste. La Ecografía es útil en precisar su diagnóstico. Los gérmenes más frecuentemente involucrados son Staphylococcus aureus, seguido por Enterococos y bacterias Gram (-). Un cultivo negativo no la descarta; por otro lado, un cultivo positivo en ausencia de signos inflamatorios indica colonización, no infección.

\section{Tratamiento (Evidencia Nivel III y IV)}

Debe iniciarse después de haber tomado Gram y cultivo del OS. Se recomienda esperar el resultado de éste a menos que la infección se considere grave, en cuyo caso se inicia tratamiento empírico. Debe evitarse el uso empírico de Vancomicina o Teicoplanina en infecciones por Estáfilococo debida a la emergente resistencia bacteriana.

Terapia empírica (antes de contar con el resultado del cultivo o si éste es (-) (ver dosis Tabla 3). Cefalosporina de primera generación o Ciprofloxacino vo.

Bacterias Gram (+): Penicilina penicilinasa resistente o Cefalosporina de primera generación vo. Si en 48- 72 hrs no mejora, agregar Rifampicina vo.

Bacterias Gram (-): Ciprofloxacino vo o Ceftazidima ip. Si es Pseudomona y en 48-72 hrs no mejora con Ciprofloxacino, agregar Ceftazidima ip. Reevaluar en 2 semanas: 
- Infección resuelta: suspender tratamiento.

- Infección mejor: continuar tratamiento por dos semanas más y reevaluar.

- Sin mejoría: considerar revisión o remoción del catéter.

\section{Terapia coadyuvante}

\section{(Evidencia Nivel III y IV)}

1. Curación frecuente del sitio de salida (1 ó 2 veces al día) mientras exista secreción importante. El sitio debe mantenerse seco.

2. Desinfección con agentes no- alcohólicos, ej. Clorhexidina. Evitar povidona yodada o agua oxigenada porque producen irritación de la piel.

3. Remover costras grandes con suero fisiológico.

4. Remover tejido granulomatoso con nitrato de plata.

5. Mantener catéter fijo (evitar exceso de movilización) y proteger del trauma.

6. Pesquisar y tratar portadores de Staphylococcus aureus nasal en paciente y familiares.

\section{Tratamiento y profilaxis de los portadores nasales de $S$. aureus (Evidencia Nivel I)}

Se recomienda realizar cultivos de secreción nasal al paciente y su cuidador tanto al ingreso al programa de Peritoneodiálisis crónica como cada tres meses. Si resulta $(+)$ se aplica Mupirocina intranasal 3 veces al día por 3 días, una vez por mes. Tomar cultivos de control al finalizar el primer tratamiento y luego cada tres meses.

\section{Estrategias de prevención (Evidencia Nivel IV)}

1. Pesquisar y tratar a los portadores de $S$. aureus.

2. Evitar la manipulación innecesaria del catéter.

3. Mantener el OS seco y limpio.

4. Utilizar técnica estéril para su curación.

5. Frecuencia de curación.

6. Desinfección con agente no irritante (clorhexidina).

7. Cubrir con apósitos no oclusivos y absorbentes.

8. Evitar baños por sumersión.

\section{Referencias}

1.- ISPD Guidelines/Recommendations, Update Peritoneal Dialysis International 2005; 25: 107-31.

2.- Recomendaciones para el inicio de la diálisis peritoneal crónica en Pediatría y para la prevención y tratamiento de las peritonitis asociadas al procedimiento. (Primer Taller de Diálisis Peritoneal, Santiago, 30 de julio de 2005. Coordinador: Dr. Francisco Cano) Arch Latin Nefr Ped 2005; 5(3): 173-80.

3.- Vargemezis $V$, Thodis E: Prevention and management of peritonitis and exit- site infection in patients on continuous ambulatory peritoneal dialysis. Nephrol Dial Transplant 2001; 16 (Suppl 6): 106-8.

4.- Piraino B: New insights on preventing and managing peritonitis. Pediatr Nephrol 2004; (19): 125-7.

5.- Strippoli G, Tong A, Jonson D, Schena F, Craig J: Catheter- Related Interventions to prevent peritonitis in Peritoneal Dialysis: a systematic review of randomized, controlled trials. J Am Soc Nephrol 2004; (15): 2735-46.

6.- Strippoli G, Tong A, Schena F, Craig J: Catheter type, placement and insertion techniques for preventing peritonitis in peritoneal dialysis patients. Cochrane Database Syst Rev 2004; 18 (4): CD004680. Review

7.- Watson A, Gartland C (European Paediatric Peritoneal Dialysis Working Group) Guidelines by an ad hoc european comité for elective chronic peritoneal dialysis in pediatric patients. http://espn.uwcm.ac.uk/ guidelines.htm

8.- Strippoli G, Tong A, Schena F, Craig J: Antimicrobial agents for preventing peritonitis in peritoneal dialysis patients. Cochrane Database Syst Rev 2004; 18 (4): CD004679. Review

9.- Bonifati C, Pansini F, Torres D, Navaneethan S, Craig J, Strippoli G: Antimicrobial agents and catheter- related interventions to prevent peritonitis in peritoneal dialysis: Using evidence in the context of clinical practice. Int J Artif Organs 2006 2006; 29 (1): 41-9.

10.- Tong $M K$, Leung $K T$, Siu YP, et al: Use of intraperitoneal urokinase for resistant bacterial peritonitis in continuous ambulatory peritoneal dialysis. J Nephrol 2005; 18 (2): 204-8.

11.- Gadallah MF, Tamayo A, Sandborn M, et al: Role of intraperitoneal urokinase in acute peritonitis and prevention of catheter loss in peritoneal dialysis patients. Adv Perit Dial 2000; 16: 233-6.

12.- Klaus G, Schafer F, Querfeld $U$, et al: Treatment of relapsing peritonitis in pediatric patients on peritoneal dialysis. Adv Perit Dial 1992; 8: 302-5.

13.- Williams AJ, Boletis I, Johnson BF, et al: Tenckhoff catheter replacement or intraperitoneal urokinase: a randomised trial in the management of recurrent continuous ambulatory peritoneal dialysis (CAPD) peritonitis. Perit Dial Int 1989; 9 (1): 65-7.

14.- Innes A, Burden RP, Finch RG, Morgan AG: Treatment of resistant peritonitis in continuous ambulatory 
peritoneal dialysis with intraperitoneal urokinase: a double-blind clinical trial. Nephrol Dial Transplant 1994; 9: 797-9.

15.- Gokal R, Alexander S, Ash S, et al: 1998. Peritoneal catheters and exit-site practices toward optimum peritoneal access: 1998 update. Official report from the International Society for Peritoneal Dialysis. Perit Dial Int 18 (1): 11-33.

16.- Warady B: Consensus guidelines for the treatment of peritonitis in pediatric patients receiving peritoneal
dialysis.Perit Dial Int 2000; 20 (6): 610-24.

17.- Piraino B, Bailie G, Bernardini J, Boeschoten E: Peritoneal Dialysis-Related Infections Recommendations: 2005 update. Perit Dial Int 2005; 25: $107-$ 31.

18.- Caring for Australians with Renal Impairment (CARI): Evidence for peritonitis treatment and prophylaxis: Prophylaxis for exit site/tunnel infections using mupirocin. Nephrology (Carlton) 2004; 9 (Suppl 3): S86-90. 